
of the Main Results from the Final Symposium

(C) 2018 by the Arizona Board of Regents on behalf of the University of Arizona. This is an Open Access article, distributed under the terms of the Creative Commons Attribution licence (http://creativecommons. org/licenses/by/4.0/), which permits unrestricted re-use, distribution, and reproduction in any medium, provided the original work is properly cited.

\title{
RELEASE AND SPECIATION OF CARBON FROM ZIRCALOY-4 IN ANAEROBIC AND HIGHLY ALKALINE CONDITIONS: COMPARISON OF SIMPLE IMMERSION AND POTENTIOSTATIC CORROSION TESTS
}

\author{
Sebastien Caes ${ }^{*}$ - Frank Druyts • Peter Thomas \\ $\mathrm{SCK} \bullet \mathrm{CEN}$, The Belgian Nuclear Research Center, Mol, Belgium.
}

\begin{abstract}
The gas release and speciation of carbon species from irradiated and unirradiated Zircaloy-4 samples, representative for the fuel cladding as used in Belgian nuclear power plants, were studied in a saturated $\mathrm{Ca}(\mathrm{OH})_{2}$ solution in anaerobic conditions. This environment is relevant for the Belgian Supercontainer design, as perceived for the geological disposal of high-level nuclear waste. To achieve this, we performed simple immersion and potentiostatic corrosion tests. Potentiodynamic polarization curves, recorded prior to the potentiostatic tests, revealed that irradiation seems to induce changes on the Zircaloy-4 corrosion behavior, such as a shift of the corrosion potential. Potentiostatic corrosion tests on unirradiated Zircaloy- 4 provided a corrosion rate of $\sim 54 \mathrm{~nm} / \mathrm{yr}$ over a 7 day-experiment, whilst a corrosion rate of only $\sim 4 \mathrm{~nm} / \mathrm{yr}$ was calculated for the irradiated sample. Gas chromatography revealed that during simple immersion tests, which lasted 195 days, hydrogen, methane, ethane, and $\mathrm{CO}_{2}$ were produced, with methane being the major compound. Assuming that all carbon released from the metal was transformed into gaseous compounds, this yields to a corrosion rate ranging from 57 to $84 \mathrm{~nm} / \mathrm{yr}$ for the irradiated sample. However, caution has to be taken on these corrosion rate and more tests should be performed to confirm these results.
\end{abstract}

KEYWORDS: carbon speciation, corrosion, electrochemical measurements, gas chromatography, geological disposal, Zircaloy-4.

\section{INTRODUCTION}

Zirconium alloys are widely used in nuclear reactors as fuel cladding because they offer a low neutron cross section, reasonable mechanical properties, and adequate corrosion resistance in high-temperature water (Garzarolli et al. 1996). From the startup of the Belgian nuclear power plants up to the year 2000, Zircaloy-4, a Zr-Sn alloy containing 1.5 wt. \% Sn, 0.22 wt. \% Fe, and 0.10 wt. $\% \mathrm{Cr}$, was the only zirconium alloy used in Belgian reactors.

Zirconium alloys possess a high corrosion resistance to uniform and localized corrosion due to the formation of a zirconium dioxide protective layer (Lefebvre and Lemaignan 1997; Mogoda 1999; Hillner et al. 2000; Motta et al. 2015). The corrosion rate-determining step is the migration of charged species (oxygen ions and electrons) across the oxide. Initially, the corrosion kinetics follow a cubic law. When the oxide layer reaches a thickness of $2-3 \mu \mathrm{m}$, a series of successive cubic curves often approximated by a linear law are observed (Hillner et al. 2000).

The influence of radiolysis on the corrosion rate and growth of the oxide is reported to be low (Lefebvre and Lemaignan 1997; Guipponi 2009). However, during nuclear fuel cycles, carbon14 can be produced mainly by the thermal neutron activation of nitrogen-14 according to the transmutation reaction ${ }^{14} \mathrm{~N}(\mathrm{n}, \mathrm{p}){ }^{14} \mathrm{C}$ (Kim 2010). In safety assessment of the geological disposal of high-level nuclear waste, carbon-14 is a critical radionuclide because of its long half-life (5730 yr) and its high mobility in the geosphere and biosphere.

During corrosion of irradiated zirconium alloys, the release of carbon can be observed (Smith and Baldwin 1993). Because nitrogen-14 is homogeneously distributed in the zirconium alloy,

\footnotetext{
*Corresponding author. Email: sebastien.caes@sckcen.be.
} 
carbon-14 is expected to be uniformly distributed in the alloy (Johnson and McGinnes 2002), leading to a potential congruent release with zirconium alloy corrosion. It has, however, been reported that carbon-14 has a higher concentration in the oxide layer compared to the underlying alloy (Yamaguchi et al. 1999), and different occupation sites were observed, such as in carbide precipitates, occluded within the oxide and/or adsorbed on the oxide surface (Smith and Baldwin 1993; IAEA 1998a; Kaneko et al. 2002; Aomi et al. 2008). Therefore, the assumption of congruent release of carbon during corrosion could only result in an approximation of the corrosion rate.

The aim of this work was to investigate the release of carbon, and carbon-14, from Zircaloy-4, representative for the fuel claddings as used in Belgian nuclear power plants, and the carbon speciation in a cementitious and anaerobic environment, which is relevant for the Belgian Supercontainer design, as perceived for the geological disposal of high-level waste (Bel et al. 2006). This was achieved by performing potentiostatic and simple immersion corrosion tests. Carbon speciation was determined by chromatographic analyses of gases produced during the corrosion tests, while the corrosion rate was calculated by electrochemical potentiostatic analysis and by carbon release.

\section{METHODS}

\section{Materials}

The unirradiated Zircaloy-4 sample is a 98-mm-long rod with an external diameter of $12 \mathrm{~mm}$ from which samples were cut in small discs. Its chemical composition is given by the "Material quality control certificate" (ASTM 2002). The irradiated Zircaloy-4 specimens originate from Belgian nuclear reactor. The upper part of the fuel tube was chosen for the corrosion tests. The fuel tube was cut in smaller pieces for the corrosion tests (Figure 1). A washing step was performed on these samples to decrease their activity by removing fission products and actinide contamination on the surface. This procedure consisted of washing the Zircaloy-4 pieces in $8 \mathrm{M}$ nitric acid under reflux for $6.5 \mathrm{hr}$, followed by rinsing them once in $1 \mathrm{M}$ nitric acid, once in ethanol and twice in demineralized water. Finally, samples are dried at room temperature. Pieces $\mathrm{A}, \mathrm{B}$, and $\mathrm{C}$ were used for simple immersion-corrosion tests and piece $\mathrm{E}$, the thicker disc, was used for the potentiostatic corrosion tests. The dimensions and contact dose rate of these samples after the washing step are summarized in Table 1.
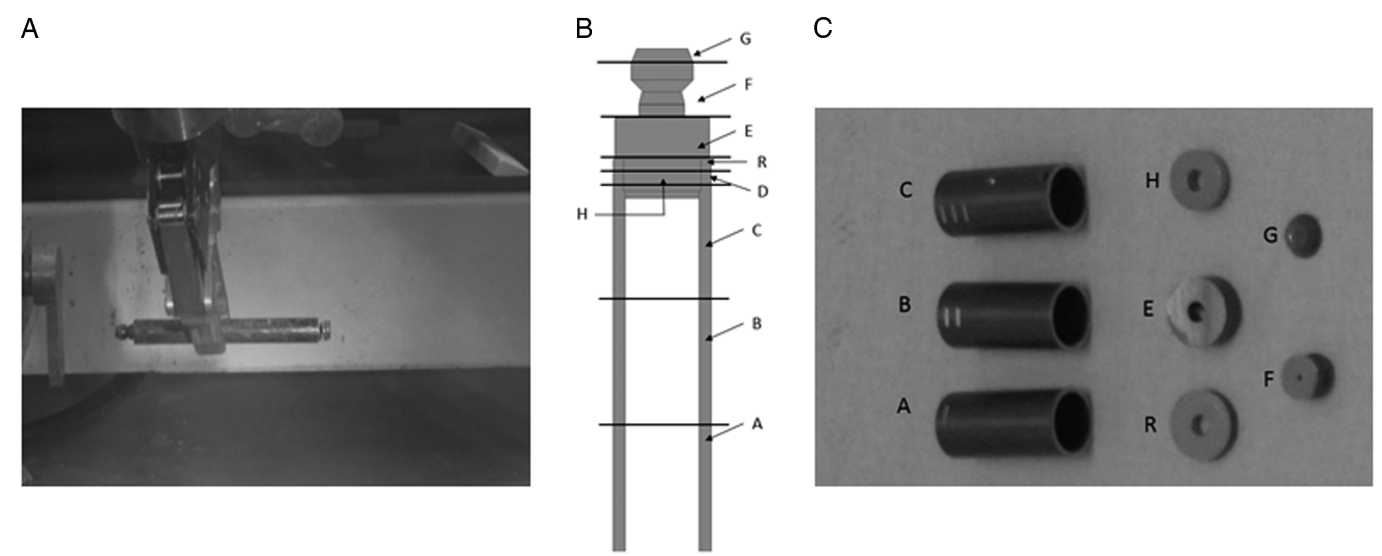

Figure 1 (A) Upper part of the irradiated Zircaloy-4 fuel cladding, (B) cutting scheme of the Zircaloy-4 cladding, and $(\mathrm{C})$ photographs of the cut Zircaloy-4 cladding (Sample D is not shown in this picture). 
Table 1 Dimensions and weight of cut irradiated Zircaloy-4 samples.

\begin{tabular}{|c|c|c|c|c|c|}
\hline \multirow[b]{2}{*}{ Sample } & \multicolumn{3}{|c|}{ Dimensions (mm) } & \multirow[b]{2}{*}{ Weight $(\mathrm{g})$} & \multirow[b]{2}{*}{ Contact dose rate $(\mu \mathrm{Sv} / \mathrm{h})$} \\
\hline & Length & Inner diameter & Outer diameter & & \\
\hline A & 20.87 & 8.4 & 9.62 & 2.3251 & 900 \\
\hline B & 20.18 & 8.4 & 9.63 & 2.2374 & 450 \\
\hline $\mathrm{C}$ & 20.3 & 8.4 & 9.64 & 2.2499 & 400 \\
\hline $\mathrm{E}$ & 4.32 & 0.5 to 2.5 & 9.66 & 1.8334 & 270 \\
\hline
\end{tabular}

\section{Corrosion Tests}

Electrochemical tests were performed with an EG\&G Model 263A potentiostat. In preparation of potentiostatic corrosion tests, potentiodynamic polarization curves were recorded at a scan rate of $0.5 \mathrm{mV} / \mathrm{sec}$ to give information on the behavior of the metal at different potentials. This helped to choose the best potential range to apply during the potentiostatic corrosion tests.

Potentiostatic measurements were conducted for preliminary speciation determination. These tests were conducted in nitrogen atmosphere at an applied potential of $-750 \mathrm{mV}$ vs. $\mathrm{Ag} / \mathrm{AgCl}$ on both unirradiated and irradiated samples in a $1450 \mathrm{~mL}$ glass vial containing three electrodes attached to the lid: (1) the working electrode (Zircaloy-4 sample), (2) the platinum counter electrode, and (3) the in-house made $\mathrm{Ag} / \mathrm{AgCl}$ reference electrode. These electrodes constitute a traditional three-electrode setup described in the general literature on electrochemistry (Tait 1994). The electrolyte used was a saturated $\mathrm{Ca}(\mathrm{OH})_{2}$ aqueous solution. For the unirradiated sample, the test was performed directly after immersion in the electrolyte. For the irradiated sample, the test was performed after the potentiodynamic polarization test, which lasted $2 \mathrm{hr}$.

Simple immersion corrosion tests aimed to investigate a more realistic corrosion behavior and associated carbon release and speciation. Simple immersion corrosion tests were carried out on irradiated samples placed in a 50-mL steel vial, equipped with a PEEK liner. The cell was filled with $35 \mathrm{~mL}$ of saturated portlandite pore water. After filling of the vials, they were screwed airtight. The tests were conducted under nitrogen conditions and lasted up to 195 days.

\section{Manufacturing of the Electrodes}

The working electrodes were manufactured by gluing a steel wire, serving as an electrical connection, to the back of the cut Zircaloy- 4 samples. The glue used was a conductive silver epoxy (type CW2400, Circuitworks). Then, the specimens were embedded in a resin under a fume hood. Finally, specimens were mechanically wet-ground, with successively finer SiC papers, down to 500 grit, and then cleaned with double distilled water and finally left to dry in an argon atmosphere.

\section{Analytical Methods}

$\gamma$-ray spectrometry analyses were performed using two different HPGe detectors: one from Canberra (CAN2) and one from Ortec (ORT1). Both detectors were energy- and efficiencycalibrated over an energy range of 60 to $2000 \mathrm{keV}$ using a $\gamma$-ray reference solution with a mixture of 10 different radionuclides. The ORT1 detector was calibrated using a 9ML01ELMA60 (2014) standard solution from LEA (Laboratoire Etalons d'Activité). The CAN2 detector was calibrated using a 12ML01ELMA60 standard source from LEA.

The nitrogen content of unirradiated samples was measured using an inert gas fusion method with a LECO TC436 model analyzer. The sample was cut into a small cube of $\sim 0.5 \mathrm{~g}$ and stored 
in acetone until the analysis. Before sample analysis, at least three nitrogen blanks were measured and the results were normalized with the blanks. The instrument was calibrated using two certified reference materials of different concentration: AR649 with a nitrogen concentration of $44 \mu \mathrm{g} / \mathrm{g}$ and an oxygen concentration of $1200 \mu \mathrm{g} / \mathrm{g}$ (Alpha Ressources) and AR503-653 with a nitrogen concentration of $70 \mu \mathrm{g} / \mathrm{g}$ (LECO). The reported lower limit of detection of the method is approximately $1 \mu \mathrm{g} / \mathrm{g}$ for $\mathrm{N}$. At least four replicate measurements were performed on each sample.

The carbon-14 computer modeling calculation was developed in the SCALE-6.1 code using the "Triton" depletion sequence.

Carbon speciation was determined by gas chromatography with a Shimadzu GC-2010 Plus type gas chromatograph (GC) equipped with a split/splitless injector, a "ShinCarbon ST" column and a pulsed discharge helium ionization detector (PDHID). The carrier gas was pure Argon. To remove any residual impurities, the carrier gas was passed through two gas purifiers (VICI Valco Instruments Co. Inc.) before it entered the GC column. A manual gas injection was made with a $500 \mu \mathrm{L}$ gas tight syringe possessing a 5-cm-long needle. The detection limits for the most likely carbon compounds were determined in two ways: (1) by means of the noise in the vicinity of the peak of interest, and (2) by measuring standards of successive lower concentration until no (clear) peak was observed anymore. Table 2 shows the detection limits, taken as the average value (rounded up) of the detection limits determined by means of both methods. The value for carbon dioxide, however, seems to be extremely high but has to be considered with caution. In fact, it does not represent the real detection limit. Because a direct injection technique of the sample is used, some ambient air will inevitably enter the column (and the detector), which results in carbon dioxide contamination.

\section{RESULTS AND DISCUSSION}

\section{Carbon-14 Specific Activity}

The activation of nitrogen-14 $\left({ }^{14} \mathrm{~N}(\mathrm{n}, \mathrm{p}){ }^{14} \mathrm{C}\right)$ is the most likely production pathway of carbon-14 in Zircaloy-4 (Wallace 1977). The nitrogen content analysis of the unirradiated Zircaloy-4 was performed on two different samples as it is the main precursor for carbon-14. The results are presented in Table 3. According to the literature (Blokhin et al. 2012) and/or technical specifications (ASTM 2013), the nitrogen content $\left(C_{N}\right)$ is usually between 40 and $80 \mu \mathrm{g} / \mathrm{g}$. Values measured for SCK•CEN samples are 2 to 4 times lower. This result leads to a decrease of the expected amount of carbon-14 inside the sample after irradiation.

Based on this nitrogen content measurement in unirradiated Zircaloy-4, an estimation of the carbon-14 amount after irradiation of the metal was obtained using a computer modeling

Table 2 List of analyzed gases and their detection limits using the Shimadzu GC-2010 Plus with the PDHID detector.

\begin{tabular}{lc}
\hline Gases & Detection limit $(\mu \mathrm{L} / \mathrm{L})$ \\
\hline Methane & 0.4 \\
Carbon dioxide & 3 \\
Ethene & 0.2 \\
Ethane & 0.2 \\
Propene & 1.5 \\
Propane & 0.75 \\
\hline
\end{tabular}


Table 3 Average nitrogen concentration $\left(\mathrm{C}_{\mathrm{N}}\right)$ and carbon-14 specific activity of Zircaloy-4 samples obtained from the computer simulation.

\begin{tabular}{lcllc}
\hline & & $\begin{array}{l}\text { Fluence } \\
\left(\mathrm{n} / \mathrm{cm}^{2}\right)\end{array}$ & $\begin{array}{l}\text { Concentration } \\
\text { of }{ }^{14} \mathrm{C}(\mathrm{wt} . \mu \mathrm{g} / \mathrm{g})\end{array}$ & $\begin{array}{l}\text { Computer simulation } \\
\text { of carbon-14 specific } \\
\text { activity }(\mathrm{Bq} / \mathrm{g})\end{array}$ \\
\hline ZR4 19430 & $17 \pm 3.9$ & $4.08 \times 10^{22}$ & $8.12 \times 10^{-2} \pm 1.86 \times 10^{-2}$ & $13,300 \pm 3000$ \\
ZR4 M92029 & $25 \pm 2.6$ & $4.08 \times 10^{22}$ & $1.19 \times 10^{-1} \pm 1.24 \times 10^{-2}$ & $19,560 \pm 2000$ \\
\hline
\end{tabular}

calculation, taking into account a standard Zircaloy-4 cladding composition and burnup of the fuel of $60 \mathrm{GWd} / \mathrm{t}_{\mathrm{U}}$, which corresponds to a total neutron flux of $4.08 \times 10^{22} \mathrm{n} / \mathrm{cm}^{2}$ for the cladding. From the calculations, it appears that only $0.5 \%$ of nitrogen- 14 produced carbon- 14 at the end of irradiation. This leads to a carbon-14 concentration ranging from $8 \times 10^{-2}$ to $1.2 \times 10^{-1} \mu \mathrm{g} / \mathrm{g}$ of Zircaloy-4 and a carbon-14 specific activity of 13,300 to 19,600 Bq/g (Table 3).

Regarding the computer simulation of the carbon-14 concentration in the Zircaloy-4 samples and their expected low corrosion rate in high $\mathrm{pH}$ solutions, the carbon-14 release should be low during the corrosion tests performed in this work. After the washing step performed on the irradiated samples, the main part of the oxide layer formed during the irradiation step, and its carbon-14, should be removed. The main part of the carbon-14 is present in the Zircaloy-4 bulk. Therefore, its release, as well as the carbon-12 release, should be congruent with Zircaloy-4 corrosion. For these reasons, this work focuses on the carbon release and not only on the carbon-14 release.

\section{Corrosion Experiments and Carbon Speciation}

Two different corrosion tests were performed in this study. Simple immersion corrosion tests were performed to obtain information on the corrosion behavior of Zircaloy-4 in realistic geological disposal conditions while potentiostatic corrosion tests were performed to determine the electrochemical behavior of the investigated material. It has to be noted that potentiostatic corrosion tests were also performed with the sole aim to accelerate the corrosion process and determine the carbon speciation. For this reason, potentiostatic corrosion tests lasted only 7 days compared to the 195 days of the simple immersion corrosion tests.

Figure 2 presents the potentiodynamic polarization curves of irradiated and unirradiated Zircaloy-4 in saturated portlandite aqueous solution. Unirradiated Zircaloy-4 exhibited a corrosion potential near $-1.04 \mathrm{~V}$ (vs. $\mathrm{Ag} / \mathrm{AgCl}$ ) and a broad passive range starting at $-0.7 \mathrm{~V}$ (vs. $\mathrm{Ag} / \mathrm{AgCl}$ ). Irradiated Zircaloy-4 showed the same kind of behavior as the one obtained for the unirradiated sample, with the presence of a broad passive range starting at around $-1.0 \mathrm{~V}$ (vs. $\mathrm{Ag} / \mathrm{AgCl})$ in the microampère current range. Note that the cathodic part of the curve was not recorded because the measurement started at the open circuit potential. It can be seen from Figure 2 that irradiation induced changes of the electrochemical behavior of Zircaloy-4. First, the corrosion potential shifted from $-1.04 \mathrm{~V}$ (unirradiated) to $\sim 1.23 \mathrm{~V}$ (irradiated) (vs. Ag/ $\mathrm{AgCl}$ ). Kim and Rebak (2009) also found such a shift and assumed that it could be caused by an increase of the conductivity of the oxide film formed on the irradiated samples. Second, the passive current decreased from $\sim 2.5 \times 10^{-6} \mathrm{~A}$ (unirradiated) to $\sim 1.5 \times 10^{-6} \mathrm{~A}$ (irradiated). This second change seems to be in contradiction with the increase in conductivity of the oxide film or the published increase of the corrosion rate of zirconium alloys induced by irradiation 


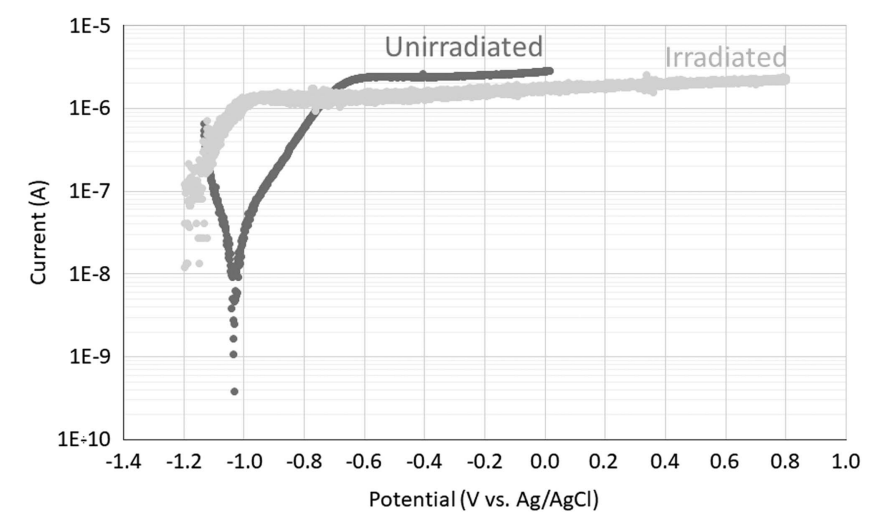

Figure 2 Polarization curves of irradiated and unirradiated Zircaloy-4 sample in saturated portlandite aqueous solution.

(Motooka et al. 2013; Tupin et al. 2015; Wang and Was 2015). However, these conclusions should be considered very carefully because only one test was performed and maybe these results all fall within the scatter of the experimental data.

From these polarization curves, a potential of $-0.75 \mathrm{~V}$ (vs. $\mathrm{Ag} / \mathrm{AgCl}$ ) was selected for the potentiostatic corrosion tests. The current is quite low at this potential $\left(10^{-6} \mathrm{~A}\right)$ but it represents the highest current in the active corrosion zone of the polarization curve of the unirradiated sample, which is expected to result in the highest corrosion rate. For the irradiated sample, this potential falls in the passive corrosion zone. However, to stay in the stability domain of water the same potential was chosen for the potentiostatic corrosion tests on the irradiated Zircaloy-4 sample.

Potentiostatic corrosion tests were conducted for approximately seven days, while sampling of the gas phase was performed regularly. The gas phase was analyzed by gas chromatography to estimate the production of carbon-based molecules during corrosion. No light carbon-based molecules, such as methane, ethene, ethane, propene, propane or carbon dioxide, were detected during these tests (Figure not shown). However, at $\sim 0.4$ min of retention, a peak resulting from the presence of $\mathrm{H}_{2}$ is observed (Figure 3). The intensity of this peak slightly increases with corrosion time up to $69 \mathrm{hr}$. Then, the intensity of the $\mathrm{H}_{2}$ peak remained stable. Indeed, a cubic law initially represents the corrosion of Zircaloy-4 at high $\mathrm{pH}$ (Kato et al. 2014). Moreover, a decrease of the current until a few nanoAmpère or less were observed after only a few hours of corrosion, confirming this cubic law (see inset of Figure 3).

From the current as a function of the time curves, it was also possible to calculate the total charge as well as the amount of corroded metal. It appeared that a corrosion rate of $\sim 54 \mathrm{~nm} / \mathrm{yr}$ is obtained if it is assumed that all the recorded current originates from the corrosion of the unirradiated Zircaloy-4. However, this corrosion rate is an upper limit because the measured current can come not only from the corrosion but also from any other electrochemical reaction at the surface of the electrode. IAEA suggested a corrosion rate of $20 \mathrm{~nm} / \mathrm{yr}$ for Zircaloy-4 (IAEA 1998b; IAEA 2006). This calculation of $\sim 54 \mathrm{~nm} / \mathrm{yr}$ looks then very high, indicating the conservative nature of this rate.

From the corrosion of the irradiated sample, a corrosion rate of $\sim 4 \mathrm{~nm} / \mathrm{yr}$ is obtained considering the same assumption. This value is lower than the one obtained for the unirradiated 


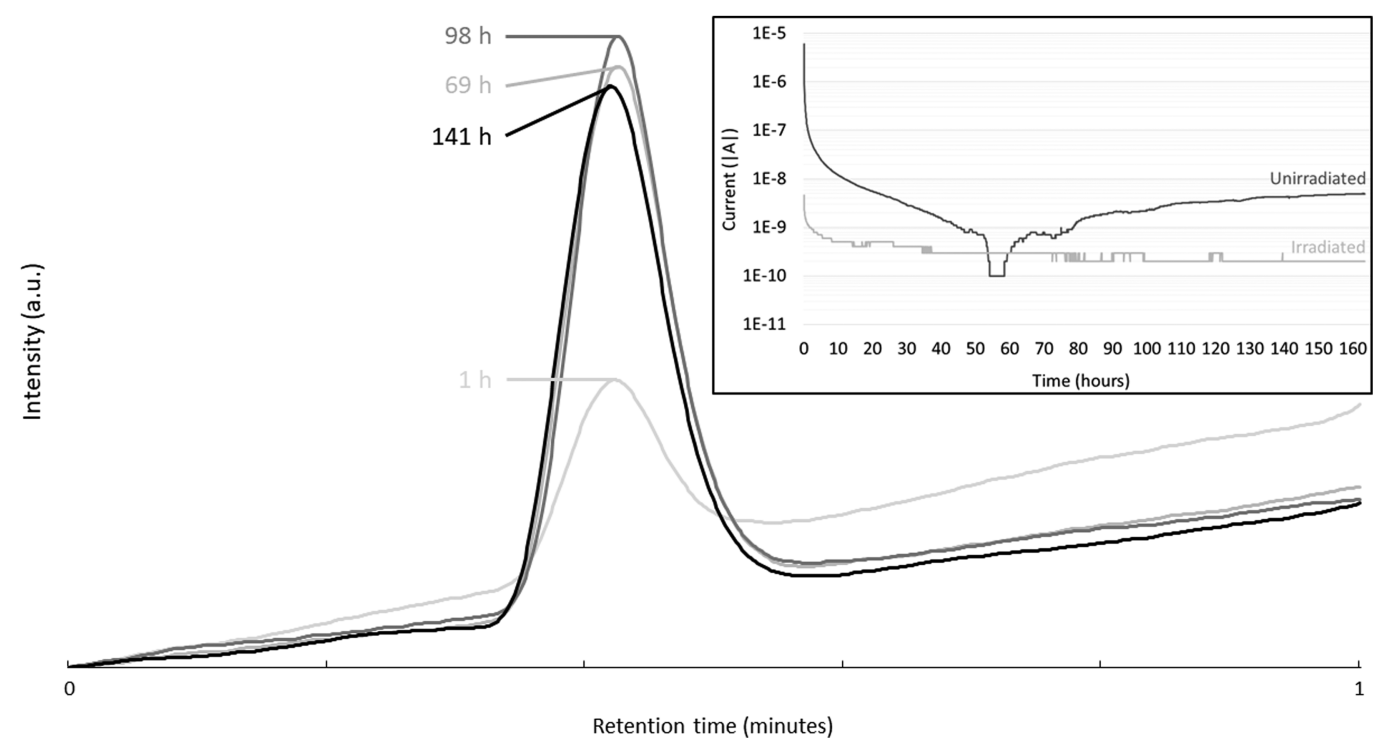

Figure 3 Gas chromatograms of gas sampling from the headspace of the potentiostatic corrosion vial at different corrosion times of the unirradiated Zircaloy- 4 sample in $\mathrm{Ca}(\mathrm{OH})_{2}$ electrolyte. Inset: Current as a function of corrosion time of the irradiated and unirradiated Zircaloy- 4 samples.

sample and than the conservative value suggested by IAEA (IAEA 1998b; IAEA 2006). This could be due to the fact that the passive layer was already present at the beginning of this test. Indeed, the potentiostatic test was performed directly after recording the polarization curve without applying an extra polishing step. Considering the short length of the corrosion exposure, the uncertainty on the obtained rate is high. In any case, the recorded values should be considered with caution and more measurements would be needed for confirmation.

Simple immersion corrosion tests were performed on irradiated samples A, B, and C (Figure 1). Unirradiated samples were not tested. After 195 leaching days, samplings from the gas phase accumulated in the headspace of the vial were analyzed by gas chromatography. Even if the corrosion rate was expected to be low, the detection and separation of peaks for carbon-based gas were obtained. The formation of those molecules is proposed to occur through mechanisms comparable to the Fischer-Tropsch synthesis (Henrici-Olive and Olive 1976; Deng et al. 1997). Chromatograms obtained for the three samples gave similar results (Figure 4; Table 4). It can be seen from Figure 4 that methane, carbon dioxide and ethene can clearly be distinguished with methane being the major contributing component. The measured concentrations are low, but are well above the detection limit, except for carbon dioxide (Table 2). Between 9 and 10 minutes of retention, a bump in the GC chromatograms is observed, which can be attributed to water. Unfortunately, this bump can interfere with the ethane peak. Therefore, it becomes impossible to know if this gas was formed (or not) during the corrosion of Zircaloy-4 samples. A peak attributed to hydrogen was also detected, however, its concentration could not be determined quantitatively.

Knowing the production of the carbon-based compounds in the gas phase and the carbon concentration in the bulk, an approximation of the corrosion rate was determined. If it is assumed that all the carbon, present in the bulk and released during corrosion, was transformed in carbon-based gas, a corrosion rate of $57 \pm 4 \mathrm{~nm} / \mathrm{yr}$ was calculated. In the case where the 


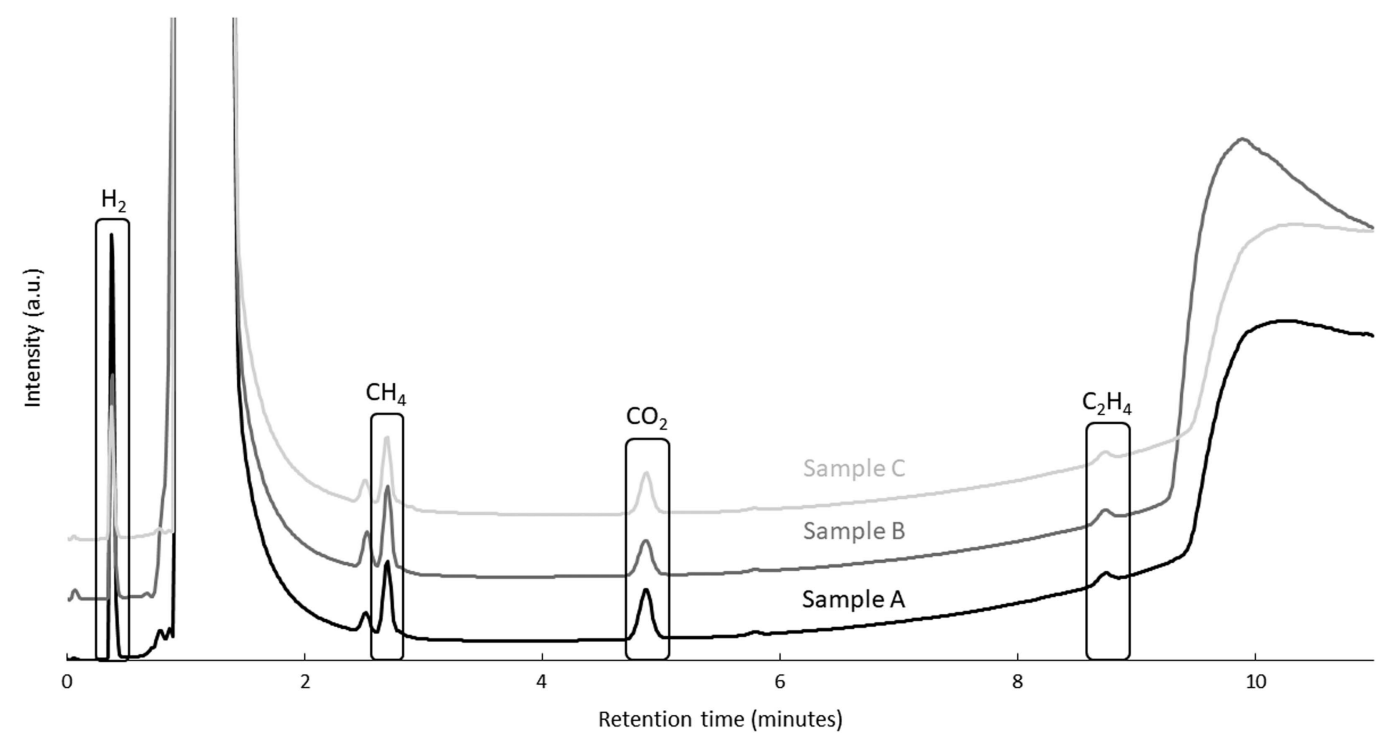

Figure 4 Gas chromatograms of gas sampling from the headspace of the simple immersion corrosion vials of the irradiated Zircaloy-4 sample in saturated portlandite pore water after 195 days.

detected $\mathrm{CO}_{2}$ was taken into account in the calculation, a corrosion rate of $84 \pm 17 \mathrm{~nm} / \mathrm{yr}$ was calculated. Indeed, the uncertainty on the $\mathrm{CO}_{2}$ concentration in the gas phase is high due to the injection method used. These values are in the same range as the corrosion rate calculated from the electrochemical measurement of the unirradiated sample, but they are significantly higher compared to the conservative corrosion rate of $20 \mathrm{~nm} / \mathrm{yr}$ suggested by IAEA (IAEA 1998b, 2006).

Carbon-based compounds are likely to be release in the liquid phase, leading to a higher corrosion rate. However, due to the high uncertainties on these measurements and/or the low concentration, the determination of the carbon and carbon-14 concentration in solution with TIC/TOC (total (in)organic carbon) and LSC (liquid scintillation counting) did not allow to obtain more information. For this reason, this study focused only on the carbon speciation and the carbon released in the gas phase.

Even if corrosion was reproducible for the three tests, this value should be considered with caution. Indeed, due to the washing step, initially performed to reduce the activity of the

Table 4 Calculated concentrations of methane, ethane, and carbon dioxide in the gas phase after simple immersion corrosion tests of Zircaloy 4 in portlandite pore water (duration 195 days).

\begin{tabular}{|c|c|c|c|c|c|c|}
\hline \multirow[b]{2}{*}{ Samples } & \multicolumn{2}{|c|}{ Methane } & \multicolumn{2}{|c|}{ Ethene } & \multicolumn{2}{|c|}{ Carbon dioxide } \\
\hline & $\begin{array}{l}\text { Measured } \\
\text { peak area } \\
\text { (a.u.) }\end{array}$ & $\begin{array}{l}\text { Calculated } \\
\text { concentration } \\
(\mu \mathrm{L} / \mathrm{L})\end{array}$ & $\begin{array}{l}\text { Measured } \\
\text { peak area } \\
\text { (a.u.) }\end{array}$ & $\begin{array}{l}\text { Calculated } \\
\text { concentration } \\
(\mu \mathrm{L} / \mathrm{L})\end{array}$ & $\begin{array}{l}\text { Measured } \\
\text { peak area } \\
\text { (a.u.) }\end{array}$ & $\begin{array}{l}\text { Calculated } \\
\text { concentration } \\
(\mu \mathrm{L} / \mathrm{L})\end{array}$ \\
\hline A & 445448 & $6.4 \pm 0.3$ & 87015 & $1.0 \pm 0.1$ & 461671 & $5.0 \pm 2.0$ \\
\hline B & 481731 & $7.0 \pm 0.4$ & 104984 & $1.2 \pm 0.1$ & 341713 & $3.2 \pm 2.0$ \\
\hline $\mathrm{C}$ & 410637 & $5.9 \pm 0.3$ & 72075 & $0.8 \pm 0.1$ & 364723 & $3.6 \pm 2.0$ \\
\hline $\begin{array}{l}\text { Mean } \\
\text { value }\end{array}$ & & $6.4 \pm 0.3$ & & $1.0 \pm 0.1$ & & $3.9 \pm 2.0$ \\
\hline
\end{tabular}


samples, the oxide layer formed at the surface of the Zircaloy-4 sample was at least partially removed, which might have led to possible changes in the corrosion rate.

Another method to calculate the corrosion rate could be the quantification of the produced hydrogen during the Zircaloy-4 corrosion. This will be discussed in a future communication.

\section{CONCLUSIONS}

This work investigated the release of carbon from Zircaloy-4 representative for the fuel cladding as used in the Belgian nuclear power plants, and the carbon speciation in a cementitious environment, which is relevant for the Belgian Supercontainer design, as perceived for the geological disposal of high-level waste. To achieve this, two different corrosion tests were performed: (1) simple immersion corrosion tests to obtain information on the Zircaloy-4 behavior in realistic geological disposal conditions; these tests were only realized on irradiated samples, and (2) potentiostatic corrosion tests to investigate the electrochemical behavior including the corrosion mechanism and speciation of light carbon molecules formation.

Before starting the potentiostatic corrosion tests, polarization curves were recorded to obtain information on the electrochemical behavior of the Zircaloy-4 samples. Irradiation seemed to induce some difference in the sample behavior such as the shift of the corrosion potential to a more reductive potential.

The analysis of the gas phase by GC, obtained with a Pulse Discharge Helium Ionization Detector (PDHID) detector, revealed the production of methane, ethene and potentially carbon dioxide after the 195 days duration of the simple immersion corrosion tests on irradiated Zircaloy-4, with methane being the major compound. Based on the measured gas concentrations, an approximation of the corrosion rate was calculated $(57-84 \mathrm{~nm} / \mathrm{yr})$. Even though no carbon-based products could be measured after the potentiostatic corrosion tests, the analysis of the electrical current produced during this test suggested a corrosion rate of $54 \mathrm{~nm} / \mathrm{yr}$ for the unirradiated sample and a lower value of $4 \mathrm{~nm} / \mathrm{yr}$ for the irradiated sample. This lower value is maybe due to the presence of a passive film formed on this sample after the potentiodynamic test. However, caution has to be taken on these corrosion rates and more tests should be performed to confirm these results. The quantification of the produced hydrogen during the Zircaloy- 4 corrosion could also be used to calculate its corrosion rate. This will be discussed in a future communication.

\section{ACKNOWLEDGMENTS}

The research leading to these results has received funding from the "European Union's European Atomic Energy Community's (Euratom) Seventh Framework Programme FP7/ 2007-2013 under grant agreement no. 604779, the CAST project". The authors gratefully acknowledge the financial support of this work by ONDRAF/NIRAS, the Belgian national radioactive waste management organization. The authors acknowledge also Pieter Schroeders, Steven Smets, Ben Gielen, Sabrina Lunardi, and Wim Verwimp for the technical support and Kevin Govers for his help with the computer simulation.

\section{REFERENCES}

Aomi M, Baba T, Miyashita T, Kamimura K, Yasuda T, Shinohara Y, Takeda T. 2008. Evaluation of hydride reorientation behavior and mechanical property for high burnup fuel cladding tube in interim dry storage. Journal of ASTM International 5(9):1-21.
ASTM B353-02. 2002. Standard specification for wrought zirconium and zirconium alloy seamless and welded tubes for nuclear service. West Conshohocken (PA): ASTM International. URL: https://www.astm.org 
ASTM B811-13. 2013. Standard specification for wrought zirconium alloy seamless tubes for nuclear reactor fuel cladding. West Conshohocken (PA): ASTM International. URL: https://www.astm. org

Bel JJP, Wickham SM, Gens RMF. 2006. Development of the Supercontainer design for deep geological disposal of high-level heat emitting radioactive waste in Belgium. Materials Research Society Symposia Proceedings 932:23-32.

Blokhin DA, Chernov VM, Blokhin AI, Denim NA, Sipachev IV. 2012. Nuclear physical properties of zirconium alloys E110 and E635 under long-term neutron irradiation in VVER-1000 reactor. Inorganic Materials: Applied Research 3:124-8.

Deng B, Campbell TJ, Burris DR. 1997. Hydrocarbon formation in metallic iron/water systems. Environmental Science \& Technology 31:1185-90.

Garzarolli F, Stehle H, Steinberg E. 1996. Behavior and properties of zircaloys in power reactors: A short review of pertinent aspects in LWR fuel. ASTM STP 1295:12-32.

Guipponi C. 2009. Effets de la radiolyse de l'air humide et de l'eau sur la corrosion de la couche d'oxyde du Zircaloy-4 oxydé [PhD thesis]. Lyon. In French.

Henrici-Olive G, Olive S. 1976. Fischer-Tropsch synthesis - molecular-weight distribution of primary products and reaction-mechanism. Angewandte Chemie International Edition 15:136-41.

Hillner E, Franklin DG, Smee JD. 2000. Long-term corrosion of Zircaloy before and after irradiation. Journal of Nuclear Materials 278:334 45.

IAEA. 1998a. Waterside corrosion of zirconium alloys in nuclear power plants. Vienna: International Atomic Energy Agency (IAEA). IAEATECDOC-996.

IAEA. 1998b. Durability of spent nuclear fuels and facility components in wet storage. Vienna: International Atomic Energy Agency (IAEA). IAEATECDOC-1012.

IAEA. 2006. Understanding and managing ageing of material in spent fuel storage facilities. Vienna: International Atomic Energy Agency (IAEA). IAEA Technical Reports Series 443.

Johnson LH, McGinnes DF. 2002. Partitioning of radionuclides in Swiss power reactor fuels. Switzerland: Nagra. Report No. 02-07.

Kaneko S, Tanabe H, Sasoh M, Takahashi R, Shibano T, Tateyama S. 2002. A study on the chemical forms and migration behavior of carbon-14 leached from the simulated hull waste in the underground condition. MRS proceedings 757:II3.8.

Kato O, Tanabe H, Sakuragi T, Nishimura T, Tateishi T. 2014. Corrosion tests of Zircaloy hull waste to confirm applicability of corrosion model and to evaluate influence factors on corrosion rate under geological disposal conditions. Materials Research Society Symposia Proceedings 1665:195-202.

Kim K. 2010. Estimation of carbon-14 in nuclear power plant gaseous effluents. EPRI Technical Report 1021106.

Kim Y-J, Rebak RB. 2009. Photo-electrochemistry of zirconium alloys in high temperature waste $-\mathrm{A}$ review. CORROSION 2009, paper no. 09417, 2226 March 2009, Atlanta, GA, USA (NACE, Houston, TX).

Lefebvre F, Lemaignan C. 1997. Irradiation effects on corrosion of zirconium alloy claddings. Journal of Nuclear Materials 248:268-74.

Mogoda AS. 1999. Electrochemical behaviour of zirconium and the anodic oxide film in aqueous solutions containing chloride ions. Thin Solid Films 357:202-7.

Motooka T, Komatsu A, Tsukada T, Yamamoto M. 2013. Pitting potential of Zircaloy-2 in artificial seawater under gamma-ray irradiation. ECS Transactions 53:25-32.

Motta AT, Couet A, Comstock R. 2015. Corrosion of zirconium alloys used for nuclear fuel cladding. Annual Review Materials Research 45:18.1-18.33.

Smith HD, Baldwin DL. 1993. An investigation of thermal release of carbon-14 from PWR Zircaloy spent fuel cladding. Journal of Nuclear Materials 200:128-37.

Tait WS. 1994. An introduction to electrochemical corrosion testing for practicing engineers and scientists. USA: Pair O Docs Publications.

Tupin M, Hamann J, Cuisinier D, Bossis P, Blat M, Ambard A, Miquet A, Kaczorowski D, Jamard F. 2015. Understanding of corrosion mechanisms of zirconium alloys after irradiation: Effect of ion irradiation of the oxide layers on the corrosion rate. ASTM STP 1543:438-78.

Wallace D. 1977. Carbon-14 production in nuclear reactors, Oak Ridge National Laboratory, Tennessee, USA, Available from: https://www.nrc. gov/docs/ML0934/ML093421400.pdf

Wang P, Was GS. 2015. Oxidation of Zircaloy-4 during in situ proton irradiation and corrosion in PWR primary water. Journal of Materials Research 30:1335-48.

Yamaguchi T, Tanuma S, Yasutomi I, Nakayama T, Tanabe H, Katsurai K, Kawamura W, Maeda K, Kitao H, Saigusa M. 1999. A study on chemical forms and migration behavior of radionuclides in hull wastes. Proceedings of the 7th International Conference on Radioactive Waste Management and Environmental Remediation, ICEM; 1999 September 26-30; Nagoya, Japan. New York: American Society of Mechanical Engineers. 